\title{
CARNAVAL E ADMINISTRAÇÃO PÚBLICA O PAPEL DOS GOVERNOS LOCAIS NA CONFIGURAÇÃO DAS FESTAS
}

Fernando Burgos Pimentel dos Santos

Fatores culturais e sociais sempre estiveram presentes nas análises sobre o carnaval brasileiro. Mais recentemente, fatores econômicos da festa também começaram a ter visibilidade. Neste artigo, analisam-se os carnavais brasileiros sob a perspectiva da atuação da administração pública em relação às festas. Mais especificamente, focalizam-se os carnavais do Recife (PE), Rio de Janeiro (RJ) e Salvador (BA). [abstract on page 278]

\section{CARNAVAL, ADMINISTRAÇÃO PÚBLICA, POLÍTICA CULTURAL, ECONOMIA DA CULTURA.}




\section{INTRODUÇÃO}

Vinculadas inicialmente, nos anos 30, ao Ministério dos Negócios da Educação e Saúde Pública, foi a gestão do ministro Gustavo Capanema (1934-1945) que propiciou apoio dos órgãos governamentais à produção e à difusão cultural. Nesse período de intenso relacionamento entre intelectuais e governo, o Estado utilizou-se da Cultura até como meio de propaganda do regime, na tentativa de formação de uma identidade nacional.

Desde então, tanto as gestões presidenciais quanto ministeriais trataram de forma diferente a questão cultural. Passando por períodos de democracia e de ditadura militar, as políticas culturais sofreram processos de continuidade e descontinuidade, tanto de programas quanto de instituições, que eram extintas e criadas para atender às novas diretrizes de governo. Em 1985 finalmente, ocorre a "independência" em relação à Educação, e é criado o Ministério da Cultura. A área sofre novo revés cinco anos mais tarde, quando, no governo Fernando Collor de Mello, perde sua condição ministerial, retomada, entretanto, dois anos depois, assim permanecendo até hoje.

Embora sejam sempre afirmadas como muito importantes, as políticas culturais ainda não recebem, na prática, atenção equivalente à de outras políticas sociais. Nos governos locais isso ocorre de maneira muito acentuada. Na maioria dos municípios brasileiros, a cultura simplesmente é ignorada ou tratada de forma secundária, servindo até para trocas eleitoreiras (FARIA \& NASCIMENTO, 2000). A grande exceção a essa tendência ocorre por ocasião das festas populares, principalmente pelo potencial desses eventos de trazer ganhos financeiros para as localidades.

No entanto, é fundamental reconhecer que, além das questões econômicas, as políticas culturais envolvem relevante componente social. Fatores como o fortalecimento de identidade, do sentimento de pertencimento e de laços comunitários, participação popular na formulação e implementação das políticas e ocupação de espaços públicos têm íntima relação com essas festas, que podem ter vínculos territoriais em diferentes escalas (locais, regionais e nacionais). Nesse cenário está inserida a maior das festas populares brasileiras, o carnaval.

\section{CARNAVAL E ADMINISTRAÇÃO PÚBLICA: UMA RELAÇÃO ANTIGA}

A análise histórica da relação entre as festas carnavalescas e os governos mostra que, na maioria das vezes, a administração pública e o carnaval estiveram sempre muito próximos, em relações às vezes consensuais, em outros momentos bastante conflituosas.

Em termos cronológicos, antes do carnaval, fazia bastante sucesso o entrudo português. Não era exclusividade dos escravos ou da população mais pobre. A elite brasileira também costumava divertir-se com brincadeiras próprias, mais "limpas" do que o entrudo popular, embora o ato de atirar objetos uns nos outros (o divertimento mais usual era atirar limões de cheiro nos desprevenidos) fosse igual. Segundo Moraes (1987), o im- 
perador d. Pedro I era um dos adeptos do entrudo, e desse entusiasmo teria sido herdeiro seu filho, d. Pedro II.

Na Bahia, em 1831, decretos provinciais determinaram que o entrudo fosse imediatamente proibido. O povo baiano, no entanto, optou por dar continuidade à festa, ignorando as ordens governamentais. E assim persistiu nos 50 anos seguintes: decretos eram periodicamente publicados e em seguida ignorados pelo povo, mesmo sob o risco de multas ou prisões (MENEZES, 1994).

No Rio de Janeiro, a elite, através de textos publicados nos jornais, criticava a "barbárie" que tomava conta das ruas das cidades, o entrudo. Cunha (2002) aponta que, na segunda metade do século XIX, vários cronistas escreviam lamentos nostálgicos sobre os carnavais do passado, em que as regras do bem-viver e as hierarquias sociais eram respeitadas. A imprensa da corte considerava intolerável a convivência anônima e etílica entre pessoas de diferentes origens e estratos sociais.

No Recife, em 1848, o juiz de direito e chefe de polícia dr. Henrique de Miranda concedia o título de "Rei do Congo" ao sr. Antonio de Oliveira. Mais do que gesto de respeito pela religiosidade e etnia africana, era uma forma de o poder público disciplinar e mesmo reprimir tais manifestações. Pois, para permitir a realização das coroações dos reis do Congo e, consequentemente, da apresentação dos maracatus, exigia-se que o rei empossado mantivesse ordem e controle sobre os demais negros (ARAÚJO, 2003). E, ao "permitir" que seus escravos participassem da festa, os senhores mostravam à sociedade sua "generosidade". Araújo (2003) cita também passagem do depoimento de um jesuíta, em 1711, afirmando que negar aos escravos a possibilidade de realizarem seus folguedos era deixá-los "desconsolados, melancólicos, de pouca vida e saúde".

Havia, entretanto, na capital pernambucana clara definição de quais manifestações eram permitidas: aquelas que não confrontavam a ordem social dominante, como a cerimônia de coroação dos reis, os cortejos de maracatu (a partir da segunda metade do século XIX), alguns batuques, as festas de Nossa Senhora do Rosário e alguns tipos de cortejos em homenagem a santos. Proibidas eram as práticas religiosas de origem africana, com a concomitante apresentação de danças e toques. Às permitidas era facultado o uso dos espaços públicos das cidades. As proibidas deviam realizar-se em espaços privados ou distantes dos centros, sujeitas à intensa vigilância e repressão policial, agregando à prática da religião ancestral dos negros caráter de clandestinidade. E por querer participar dos festejos públicos e através deles obter reconhecimento, a maior parte dos grupos de negros e mulatos cumpria todas as exigências e com muita ordem e zelo realizava suas apresentações públicas (ARAÚJO, 2003).

No período da Regência, com a instabilidade política do Império, as autoridades públicas passaram a controlar muito mais as aglomerações. No Recife, sobretudo os encontros de escravos foram severamente controlados e, muitas vezes, abolidos. Além disso, imperava na Igreja católica local orientação bastante conservadora. Máscaras, danças, músicas e demais manifestações artísticas foram proibidas. Com isso, o entrudo, que já era apontado como sinal de atraso e ignorância do povo, passou a ser também alvo de 
perseguições políticas e religiosas. Em 1854, fato exemplar ilustra a perseguição às manifestações populares: os escravos foram proibidos de usar máscaras nas festas carnavalescas. Os membros da elite branca, dessa maneira, supostamente correriam menos riscos de agressão por escravos, disfarçados pelas máscaras (ARAúJO, 2003). Apesar da vigilância da elite e da perseguição policial, o povo, entretanto, continuou a festejar o carnaval nas ruas, ainda que, para isso, tivesse que se deslocar para regiões menos centrais.

Ao mesmo tempo em que reprimiam certas manifestações, os governantes procuravam fornecer algum tipo de estrutura para a realização do carnaval. Por exemplo, a necessidade de apoio das empresas de transporte - públicas ou privadas - para ajudar no deslocamento dos foliões começou a tornar-se constante. Moraes (1987) mostra que, em 1888, a Cia. de Carris Urbanos colocava bondes extras no período carnavalesco, para melhor servir aos foliões cariocas.

Em Salvador, o entrudo popular era combatido e, por isso, ocorria mais no final da tarde ou no início da noite, quando os senhores já estavam em suas casas, e os escravos podiam brincar. Ainda assim eram reprimidos pelas autoridades. Como alternativa, nas duas últimas décadas do século XIX começam a surgir os desfiles carnavalescos de organizações negras com seus batuques. Por trás da permissão para esse desfile estava a intenção de extinguir o entrudo. Pouco disposta a conviver com isso, a elite baiana passa a realizar seu carnaval em salões e clubes sociais. E a assistir ao desfile do corso na região central da cidade, na Rua Chile (MIGUEZ, 2003).

Igualmente, no início do século XX, a burguesia, no Rio de Janeiro, procurava formas de acabar com a bagunça, tornando a festa mais "culta". Ferreira (2004) aponta sutil alteração na atitude da elite que, ele informa, mudou sua estratégia. Em vez de tentar "civilizar" o carnaval, como o fizera na segunda metade do século XIX, a nova tática era reorganizar a festa dentro de seus conceitos, incorporando a multiplicidade de brincadeiras. E muitas diversões, até então consideradas entrudo, passaram a ser tratadas como carnaval.

Nessa mudança de atitude, a festa foi dividida em dois carnavais: o grande e o pequeno. $O$ pequeno carnaval era realizado basicamente por negros e mulatos, mas também por descendentes de imigrantes; seus participantes não dispunham de recursos para gastos. Utilizavam fartamente, entretanto, danças e músicas, atestando característica ímpar à festa. Com essa animação, aos poucos foram conquistando o direito de desfilar no Centro até que, em 1910, desfilaram na Avenida Central (mais tarde denominada Rio Branco). Mesmo no dia considerado "fraco" - a Segunda-Feira Gorda - não tardou que os grupos (ranchos e blocos) do pequeno carnaval fossem considerados uma das grandes atrações da festa (QUEIROZ, 1999).

Em 1927, Prado Júnior assume o comando do Rio de Janeiro. Segundo Farias (2006), essa gestão tinha o objetivo de explorar a aparência da cidade como paisagem postal e também dotá-la de equipamentos que estimulassem o turismo. Logo no início do governo, aponta Ferreira (2004), há mostra de como o carnaval se estava transformando em importante evento para o governo, posto que uma das primeiras providên- 
cias foi aumentar o auxílio dado aos desfiles das Pequenas Sociedades, clara demonstração da importância que os grupos populares - essência do carnaval espontâneo e genuinamente brasileiro - vinham adquirindo junto às autoridades. Assim começou a se formar a imagem do Rio de Janeiro como a "cidade do samba", projetada especialmente no exterior.

No âmbito federal, a chamada Era Vargas tinha como uma de suas características a busca de identidades e principalmente da consolidação de uma identidade nacional brasileira. O momento era de centralização política autoritária e de construção de ideário de nação firmado, entre outros aspectos, na identidade cultural. Assim, questões referentes à cultura da população tornaram-se decisivas nesse processo. Os aspectos "nacionais" tinham mais relevância do que os regionais. E, na hora em que foi preciso escoIher quais aspectos regionais seriam elevados à condição de símbolo da brasilidade, muitas manifestações que ocorriam no Rio de Janeiro (capital do país na época) já recebiam significativo destaque e, dessa forma, foram privilegiadas. Assim, o samba e o formato do carnaval carioca foram nacionalizados e transformados em patrimônio cultural nacional.

Um dos órgãos responsáveis pelo fortalecimento da identidade nacional foi o Departamento de Imprensa e Propaganda (DIP), responsável pela censura de atividades artísticas e pela organização do programa oficial de radiodifusão do governo. Essa influência estendeu-se também ao carnaval. Soihet (1998) mostra que o DIP chegou a criar um dispositivo que obrigava as escolas de samba a utilizar temas nacionais em seus enredos. Segundo Moraes (1987), inicialmente grande parte das músicas de carnaval era direcionada às questões políticas. No entanto, com o DIP e o Estado Novo, os compositores não podiam fazer qualquer crítica ao governo, devendo apenas elogiar Getúlio Vargas. Os compositores, assim, tiveram que buscar temas outros, como a cor da pele, as mulheres louras ou morenas, os barrigudos, os carecas, os puxa-sacos, a favela, o morro, amores infelizes e abandonos.

Almeida (2003, p.19-20) sugere que, na década de 1930, houve a "invenção da tradição": "É quando se criam os mitos de origem e continuidade, quando o Estado fixa o padrão do carnaval carioca, justamente após a conquista do direito de desfilar no Centro da cidade pelos negros e mulatos".

Essa retrospectiva histórica pretendeu mostrar como o carnaval sempre esteve muito próximo da administração pública. A partir deste ponto, serão detalhados como essa relação ocorre atualmente em três grandes cidades (e carnavais) brasileiros.

\section{O FORMATO ATUAL DOS MAIORES CARNAVAIS BRASILEIROS}

Há muitos carnavais no Brasil, cada um com sua história. Os maiores atualmente são os de Recife, Rio de Janeiro e Salvador. Além das características próprias, é importante destacar que as relações com os governos locais também são muito diferentes, dependendo da localidade. ${ }^{1}$ Cada qual tem suas particularidades, que serão resumidamente descritas aqui. 
1 Em Santos (2008), há uma análise sobre o carnaval de Santos (SP), em que, por uma série de acontecimentos políticos, foram proibidos o desfile das escolas de samba e o carnaval. Em 1999, por não haver acordo entre a Prefeitura e as escolas de samba sobre o local onde realizar o desfile, o carnaval santista, com história há mais de 50 anos, não foi realizado, causando grande comoção na cidade e sobretudo nas comunidades historicamente ligadas ao samba. E só em 2006 os desfiles voltaram a acontecer.

20 termo multicultural neste texto refere-se à forma como a prefeitura e a população local denominam a festa recifense.

\section{RECIFE}

O carnaval recifense é fator fundamental para a preservação e o resgate das tradições locais. E aí reside o diferencial dessa festa, na comparação com outros municípios brasileiros em que o carnaval também tem características marcantes. 0 grande comandante da festa é o frevo, embora muitos outros ritmos estejam presentes. São inúmeras as diferentes apresentações de maracatus, troças, caboclinhos, ursos, bois, blocos, orquestras e outras agremiações. Também muitos artistas de renome, nacional e internacional, marcam presença. É o que a Prefeitura da Cidade do Recife chama de Carnaval Multicultural. ${ }^{2}$

A organização da festa é bastante complexa. Em 2007 existiam na região central (incluindo o Bairro do Recife ou Recife Antigo) oito polos de diversão. Além disso, confirmando a intenção de descentralizar a festa (deslocando parte dela do Centro da cidade para os bairros periféricos), foram criados mais oito polos descentralizados. Em cada um desses 16 polos há programação diferente, com ritmos variados e respeitando as tradições locais. Os artistas mais famosos fazem shows em vários polos, permitindo à população assisti-los sem necessidade de deslocarse para o Recife Antigo ou Bairro do Recife. A decisão de descentralizar os polos de animação ocorreu na gestão do prefeito João Paulo (2001-2008), do Partido dos Trabalhadores. Dessa forma a festa pernambucana assegura a participação de todos, indepen-

dentemente da classe social ou capacidade de pagamento. Todos os eventos organizados pela prefeitura são gratuitos.

A organização interna da prefeitura conta com comissão responsável pela divisão dos principais eventos culturais da cidade em três ciclos: carnavalesco, junino e natalino. É essa comissão que, juntamente com a do carnaval, organiza a festa. Um conseIho local escolhe a programação do carnaval e a prefeitura contrata diretamente os artistas que irão-se apresentar.

Analisando a festa da capital pernambucana é possível afirmar que a prefeitura local - principalmente por intermédio da Secretaria de Cultura do Recife - tem papel de protagonismo, tanto na organização da festa como no fomento e estímulo às agremiações locais e grupos populares.

\section{RIO DE JANEIRO}

O carnaval carioca é, sem dúvida, o que atrai a maior atenção da mídia nacional e estrangeira. Conforme já mencionado, o fato de o Rio de Janeiro ser a capital federal na primeira metade do século passado, explica em grande parte a escolha do padrão carioca de carnaval como nacional. Assim, os desfiles das escolas de samba foram (e ainda são) o 
símbolo do carnaval brasileiro. Nesse processo, a chamada "profissionalização" do desfile e das escolas de samba é considerada marco importante por muitos pesquisadores.

Em entrevista concedida ao autor no final de 2007, Hiram Araujo afirma que a partir de 1984, a construção do sambódromo, no governo de Leonel Brizola, ajudou a concretizar a chamada "libertação econômica" das escolas. E com a criação da Liga das Escolas de Samba do Rio de Janeiro - Liesa, iniciou-se a chamada "era empresarial", em que as escolas passaram a gerir diretamente seus interesses, suas disputas e seus desfiles.

De acordo com esse autor, a primeira administração municipal de César Maia, em 1992, trouxe outra mudança importante, com o compromisso do prefeito de "privatizar" o carnaval carioca. Desde então a Liesa é a grande responsável por toda a administração do desfile das escolas de samba. Segundo Farias (2006), por ser proprietária da passarela, a prefeitura fica responsável por organizar e preparar a infraestrutura operacional do evento, através da RioTur. A Liesa, por sua vez, encarrega-se da parte "artística" da festa, incluindo os desfiles e os jurados. No entender de Hiram Araújo, com a criação da Cidade do Samba, em 2005, ocorreu uma "libertação estética", já que os carnavalescos passaram a contar com "um lugar de superprodução, de ponta, que são as fábricas de carnavais, com todas as condições técnicas do mundo moderno". A Cidade do Samba foi construída pela Prefeitura, que montou toda a estrutura, mas o aparelhamento foi feito pela Liesa, que paga os impostos municipais devidos.

Atualmente, o custo da realização de um desfile competitivo gira em torno de cinco ou seis milhões de reais. A venda de ingressos é uma importante fonte de arrecadação das escolas. Farias (2006) aponta que uma das formas que as escolas têm utilizado para financiar seus desfiles é a comercialização das apresentações, por meio da venda de ingressos para os ensaios, das fantasias para o desfile, ou mesmo o "patrocínio" de alguns enredos. Governos estaduais, nacional e internacionais, além de empresas privadas, procuram as escolas buscando a visibilidade que o evento e sua transmissão televisiva podem trazer.

Paralelamente aos desfiles, há o chamado carnaval popular do Rio de Janeiro. Desde que a Banda de Ipanema foi formada, em 1965 (FERREIRA, 2004), surgiram diversos blocos de rua (Suvaco do Cristo, As Carmelitas de Santa Teresa, Simpatia é Quase Amor e outros), que se juntaram aos tradicionais, como o Cordão do Bola Preta, que desfilou pela primeira vez em 1918. Embora façam sucesso, principalmente por relembrar os carnavais de outrora, por muito tempo foram tratados como residuais em relação à grande festa da Marquês de Sapucaí.

Isso, entretanto, tem mudado, com os olhares do governo, da imprensa e da sociedade carioca em geral voltando a pousar atentamente no carnaval de rua. Prova dessa retomada de interesse é que em agosto de 2007 o Ministério da Cultura, através do programa Cultura e Pensamento, promoveu seminário sobre o carnaval de rua do Rio de Janeiro, denominado "Carnaval do Brasil". No documento-síntese elaborado ao final do encontro, além de uma série de propostas relativas à infraestrutura e à organização do car- 
naval de rua, outras diziam respeito aos financiamentos públicos e privados da festa. Um dos pressupostos foi a proporcionalidade de financiamento entre o "carnaval dos desfiles" e o "carnaval de rua".

\section{SALVADOR}

Segundo Fischer (1997), a cultura de Salvador deve ser entendida de forma abrangente, pelo modus operandi da população em geral, com identidade cultural multifacetada e diversificada, com sólidas raízes na cultura negra. A autora afirma que a cultura é a expressão da identidade da cidade, tornando-a única. E prossegue com a argumentação de que as manifestações culturais ocorrem na rua, permitindo profunda miscigenação e intercâmbio cultural.

No entanto, em termos carnavalescos, pode-se afirmar que esse processo de miscigenação e intercâmbio cultural tem sido prejudicado. Em Salvador os trios elétricos passaram a fazer parte de um projeto hegemônico, e a festa, quase completamente "privatizada", é gerida por um forte grupo empresarial, unindo interesses com grandes gravadoras. Segundo Gonçalo Junior (2007), ao voltar ao governo do estado em 1990, Antonio Carlos Magalhães soube capitalizar o fenômeno da música baiana, transformando-a em produto de turismo. E, ao mesmo tempo, ao dar-lhes ampla liberdade para que gerenciassem o carnaval, cooptou artistas, produtores e empresários de blocos.

Este é o resultado da "organização profissional e comercial" que a festa baiana adquiriu. Ao reunir, em sua maioria, pessoas capazes de despender grandes quantias para comprar o abadá, os grupos configuram sua composição: majoritariamente jovens brancos das regiões Sul e Sudeste. A Empresa Central do Carnaval comercializa e centraliza a venda dos abadás dos principais trios elétricos. Do outro lado está o "folião pipoca", ou seja, aquele que fica do lado de fora dos cordões de isolamento desses principais blocos - aqueles com os abadás mais caros -, sem condições de acompanhar de perto a passagem dos principais trios elétricos e de seus abastados foliões.

Existem basicamente três tipos de trios elétricos desfilando atualmente em Salvador. No primeiro, os chamados trios independentes, que têm esse nome por não se vincular a nenhuma entidade carnavalesca; eles não utilizam nenhum tipo de corda nem seguranças, permitindo que os "foliões pipoca" brinquem à vontade. Alguns deles: Trio Expresso 2222, de Gilberto Gil, o Trio Independente, de Daniela Mercury, e o Pipocão, de Carlinhos Brown. Os do segundo tipo são os blocos alternativos, que desfilam entre a quinta-feira e o sábado de carnaval, com abadás de preços menores. Os do terceiro são os chamados blocos de trio. Para participar deles é necessário usar os abadás e adereços característicos de cada um. Os desfiles dos blocos de trio ocorrem principalmente no domingo, na segunda e na terça-feira.

Em 2007, a distribuição geográfica da festa manteve-se praticamente igual à dos anos anteriores, ocupando a área tradicional do desfile, da Praça da Sé (Centro) à Avenida Ademar de Barros (Ondina), que foi dividida em três circuitos, Batatinha, Osmar e Dodô. O circuito Dodô (Barra/Ondina) continua sendo o mais procurado do carnaval de 
Salvador, concentrando a maioria dos camarotes privados e das instalações das redes de televisão.

Para disciplinar e regular esses desfiles e outras atividades relacionadas ao carnaval, como convênios e subsídios, trios independentes, estrutura física e ambulantes, o município conta com o Conselho Municipal do Carnaval, criado pela Lei Orgânica 4.538/92. O Comar é composto por 25 segmentos, entre órgãos públicos e entidades civis. A execução das atividades carnavalescas, porém, fica sob a responsabilidade da Emtursa; portanto, o poder público participa basicamente fornecendo a infraestrutura necessária para que os trios elétricos possam desfilar.

Apesar de despertar bem menos interesse, Salvador, assim como Recife, tem procurado, recentemente, descentralizar um pouco seu carnaval, levando-o para os bairros. Em 2007, por exemplo, 12 atrações foram distribuídas em cinco bairros (Itapuã, Pau da Lima, Cajazeiras, Liberdade, Periperi). Dados da Emtursa (2007) registram média diária de 15.000 a 20.000 pessoas em todos os bairros. Além disso, também houve atrações na Praça Castro Alves e no "Palco do Rock", localizado no Piatã. Essa intenção de descentralização, no entanto, ainda precisa de muito apoio para consolidar-se.

\section{CARNAVAL: POLÍTICA PÚBLICA DE CULTURA OU DE TURISMO?}

Conforme observado até aqui, normalmente toda a estrutura responsável pela organização do carnaval, dentro da administração pública, fica nas áreas de cultura ou de turismo. Nas cidades estudadas, além de formatos distintos, os carnavais estão igualmente vinculados a órgãos públicos diferentes. A Tabela 1 mostra essa diferença, assim como outras características gerais das festas:

\begin{tabular}{|l|l|l|l|}
\hline & Recife & Rio de Janeiro & Salvador \\
\hline Atração principal & Festa “multicultural” & $\begin{array}{l}\text { Desfile de escolas } \\
\text { de samba do grupo } \\
\text { especial }\end{array}$ & Trios elétricos \\
\hline $\begin{array}{l}\text { Acesso à atração } \\
\text { principal }\end{array}$ & $\begin{array}{l}\text { Predominantemen- } \\
\text { te pago }\end{array}$ & $\begin{array}{l}\text { Predominantemen- } \\
\text { te pago }\end{array}$ \\
\hline Principal organizador & Prefeitura & Liesa & Grupos privados \\
\hline $\begin{array}{l}\text { Órgão público } \\
\text { responsável }\end{array}$ & Secretaria de Cultura & RioTur & Emtursa \\
\hline \multicolumn{2}{|c|}{ Tabela 1: Comparação resumida dos carnavais. Fonte: elaboração própria } \\
\hline
\end{tabular}

Fica evidente que, apesar de o carnaval e suas principais atrações poderem ser organizados por grupos privados - casos do Rio de Janeiro e de Salvador -, a estrutura da festa é organizada por algum órgão público, que se responsabiliza pelo festejo. Enquanto no Recife, isso cabe à Secretaria Municipal de Cultura, no Rio de Janeiro e Salvador, a responsabilidade é das empresas públicas de turismo. No Recife, apesar da denominação "Carnaval Multicultural", a Secretaria de Cultura do Recife não menospreza suas potencialidades turísticas. Nos últimos anos, por exemplo, tem ido constantemente a algumas 
capitais brasileiras (como São Paulo e Brasília) para fazer a festa de lançamento e divulgar o carnaval recifense. A aposta da Secretaria, realizando essa festa no segundo semestre do ano, é que os foliões, entrando em contato com os diferentes ritmos presentes na capital pernambucana, planejem sua viagem de carnaval para o Recife.

No Rio de Janeiro, o carnaval tem, sem qualquer dúvida, grande apelo turístico. $\mathrm{E}$ por isso é promovido pela RioTur. Esse enfoque turístico evidenciou-se em finais de 2007, quando surgiram diversas reclamações sobre a data do carnaval de 2008: logo no início do mês de fevereiro - essa data seria prejudicial ao setor turístico, uma vez que o fluxo de viajantes diminuiria em virtude das inúmeras despesas oriundas das férias de verão e do início do ano. Ainda analisando o Quadro 1, o acesso à atração principal é pago por aqueles que querem assistir aos desfiles, mas para quem vai desfilar pode ser gratuito, como para alguns membros das escolas de samba envolvidas.

Em relação a Salvador, Barbalho (2004) afirma que o turismo na Bahia sempre teve mais importância do que os aspectos culturais. Segundo o autor, ao ser criada em 1995 a Secretaria de Cultura e Turismo do Estado (SCT), o segmento de turismo e lazer teve hegemonia sobre o segmento de cultura e memória. Argumenta que o primeiro secretário, Paulo Gaudenzi, veio da Bahiatur, empresa governamental de apoio ao turismo. E aponta: "A Bahia (sua gente, sua cultura, sua natureza) é apresentada dessa forma como um produto, e dos melhores, no mercado do turismo globalizado" (BARBALHO, 2004 , p. 160). E, conforme já mencionado, para participar com abadá dos principais trios elétricos, é preciso pagar, embora haja outros trios, cuja participação é gratuita.

O debate quanto a qual secretaria ou área o carnaval deveria estar subordinado, relembra o debate de Canclini (1982) entre étnico e típico. Segundo esse autor, o setor de turismo acaba provocando unificação artificial da cultura de um povo ou localidade. Acaba, assim, omitindo as diferenças e contradições existentes. Cria-se o típico, resultado da abolição das diferenças e da subordinação a um tipo comum, com traços específicos de cada comunidade.

Giménez (1979) faz outro tipo de análise, também útil. Ao diferenciar as festas camponesas tradicionais mexicanas das festas urbanas, aponta que, naquelas predomina a lógica do valor de uso, sendo consequentes as festas participativas e não as festasespetáculo. Já nas festas urbanas predomina a lógica do valor de troca, decorrendo daí a festa-espetáculo, que é "consumida" em vez de "participada". De acordo com essa abordagem, pode-se dizer que o carnaval, enquanto festa cultural, estaria mais próximo da lógica do valor de uso e, como atrativo turístico, mais próximo do valor de troca.

\section{É POSSÍVEL FALAR EM ECONOMIA DO CARNAVAL?}

O carnaval chama a atenção em diversos aspectos. Sem dúvida é excelente oportunidade de resgatar tradições, preservar a cultura local e reafirmar os estreitos laços de amizade entre as comunidades que dele participam - mas é também excelente oportunidade de geração de trabalho e renda, o que nem do ponto de vista dos governos, nem daquele da população constitui novidade. Ferreira (2004) cita anúncio num jornal da 
época de quartos para os foliões se trocarem, mostrando que o carnaval já era considerado um bom negócio, em 1848.

Até o lança-perfume trazia muitos lucros ao carnaval. Em 1911, o povo consumiu mais de cinco mil contos em lança-perfume. O preferido era produzido pela empresa suíça Rodo que, nesse mesmo ano, recebeu encomenda de 300 libras do produto. A compra foi considerada tão extraordinária, que um representante da Rodo foi enviado ao Brasil, para assistir ao carnaval (MORAES, 1987). É a prova de que não eram apenas as grandes empresas nacionais que se beneficiavam do carnaval. Até as estrangeiras se aproveitavam da festa!

Apesar de o comércio informal constituir, historicamente, parte das comemorações carnavalescas, as referências à potencialidade econômica do carnaval estão sempre diretamente relacionadas ao imenso fluxo de turistas, às imagens dos grandes hotéis, das companhias aéreas e dos restaurantes. No entanto, ainda é raro ler ou ouvir comentários sobre trabalhadores informais e famílias que aproveitam o evento para aumentar sua renda. E o poder público, em geral, também parece pouco disposto a tratar o tema com a relevância que merece.

No Brasil, estudos sobre os aspectos econômicos da cultura ainda são escassos. Se existe essa dificuldade em termos da cultura em geral, a situação é ainda mais grave em relação ao carnaval, uma vez que mesmo investigando os três maiores polos carnavalescos brasileiros, há pouquíssima preocupação com a precisão das informações sobre o impacto dessa festa nas localidades. ${ }^{3}$ Para analisar a relação entre o carnaval e o desenvolvimento econômico local foram observadas três dimensões, que poderiam ser incorporados num debate mais sistematizado sobre a economia do carnaval, como subproduto da economia da cultura.

A primeira dimensão é a da geração de trabalho e renda. Dos dados analisados chama atenção o número de ocupa3 Recentemente, Luiz Carlos Prestes Filho organizou o livro Cadeia produtiva da economia do carnaval (2009), em que descreve a festa como cadeia produtiva. ções geradas durante o carnaval: em Salvador, por exemplo, foram criados 174.743 postos de trabalho, referindo-se, porém, $52 \%$ deles aos cordeiros responsáveis por segurar a corda que separa os foliões com abadás dos chamados "foliões pipoca" -, que recebiam apenas $\mathrm{R} \$ 2,25$ por hora de trabalho.

Em relação ao desfile do grupo especial do Rio de Janeiro, como já mencionado, a venda de ingressos representa importante fonte de recursos para as escolas. De acordo com os dados de 2001 a 2006, a arrecadação da Liesa com a comercialização dos ingressos, praticamente dobrou no período, atingindo $\mathrm{R} \$ 38.285 .065,00$ no último ano pesquisado.

A segunda dimensão explorada é a dos patrocinadores ou do patrocínio que cada uma das festas recebe. Em Salvador, para a organização do carnaval, a prefeitura comercializa cotas de patrocínio por meio de marketing direto. Já a prefeitura do Recife capta recursos de maneiras diversas, dependendo do patrocinador. No período de 2003 a 
2007, o patrocínio via Lei Rouanet foi o mais relevante, com 53,9\% do total dos recursos captados. Nesse período, pouco mais de três milhões de reais foram investidos pela Ambev, através de seu segmento Cervejas - desse total, $R \$ 1,74$ milhão (57\%) através da Lei Rouanet. A análise do resultado econômico-financeiro da Ambev - através dos indicadores Volume Comercializado e EBITDA (Earnings before interest, taxes, depreciation and amortization) - parece evidenciar a distorção provocada pela Lei Rouanet. Isso significa que, ao patrocinar a festa, a empresa obtém benefícios fiscais, por um lado. E, por outro, tem também um excelente nível de vendas, já que os comerciantes ficam obrigados a comprar apenas produtos da empresa e nem sempre em condições favoráveis ou justas. A Ambev, portanto, ganha nas "duas pontas", e, nesse sentido, apontá-la como uma das maiores beneficiárias do carnaval não parece exagero.

A terceira dimensão é do impacto da economia formalizada nas finanças municipais. É notório que as prefeituras investem grandes quantias na organização das festas, esperando que os valores retornem aos cofres públicos, através da arrecadação de impostos. No entanto, estudos realizados pela Assembleia Legislativa da Bahia mostram que o carnaval soteropolitano arrecada em impostos e tributos aproximadamente $10 \%$ dos recursos investidos pela prefeitura. Uma análise detalhada das finanças municipais do Recife, através dos dois principais impostos municipais, o Imposto Predial e Territorial Urbano - IPTU e o Imposto Sobre Serviços de Qualquer Natureza - ISSQN, mostrou não ser possível diagnosticar o impacto do carnaval nas contas públicas (SANTOS, 2008).

\section{CONSIDERAÇÕES FINAIS}

Se é consensual a alta relevância de políticas públicas de cultura, podemos pensar igualmente na relevância de políticas públicas de carnaval, notadamente no âmbito local. É preciso também analisar os carnavais brasileiros, considerando-os objetos de política pública. Embora abundem estudos sociológicos e antropológicos dessa festa, as relações entre governos e carnaval dificilmente são abordadas como temática principal. E a sensação é de que ainda há muito a ser pesquisado utilizando esse olhar da administração pública e sua interface com outras políticas públicas.

Estudos de políticas raciais poderiam apontar se o carnaval é, verdadeiramente, um momento nacional em que as raças de fato interagem, deixando de lado históricos preconceitos brasileiros. Estudos de gênero também propiciariam pesquisas interessantes, que busquem identificar o papel das mulheres em toda a cadeia produtiva do carnaval.

Outra vertente possível seria a análise das festas carnavalescas como processos de disseminação de políticas públicas. Depois da construção do sambódromo carioca, muitas cidades decidiram criar seu próprio local de apresentações carnavalescas, buscando imitar, além do padrão de carnaval, sua estrutura para desfiles. Mais recentemente, o modelo de Salvador está sendo recriado em cidades de diferentes portes populacionais, com a realização das micaretas. 
No entanto, parece mais urgente a realização de pesquisas consistentes, capazes de avaliar e quantificar corretamente a chamada economia do carnaval. Todos os anos, durante os preparativos da festa, os veículos de comunicação citam números impressionantes, gerados pelas festas. Mesmo o retorno financeiro para os cofres municipais, através de arrecadação tributária, é precariamente estimado. Enquanto a maioria dos que trabalham no carnaval recebem ínfima remuneração, os patrocinadores acabam sendo os grandes beneficiários da festa, com enormes ganhos financeiros na comercialização de seus produtos.

O desafio para as prefeituras, então, é identificar o "pacote mínimo" de medidas a adotar, objetivando o aumento dos efeitos econômicos do carnaval, principalmente para as classes mais pobres e vulneráveis, e respeitando as especificidades de cada município. E através de políticas públicas voltadas para o carnaval, estimular: o sentimento de pertencimento - através do reconhecimento da história e dos valores de uma determinada comunidade; a conscientização do povo; a participação popular; e, a apropriação de espaços públicos e a disposição de compartilhá-lo com diferentes pessoas.

\section{REFERÊNCIAS BIBLIOGRÁFICAS}

ALMEIDA, Jaime de. Uma teoria da festa: o carnaval brasileiro. In ALMEIDA, Luiz Sávio de; CABRAL, Otávio e ARAÚJO, Zezito. O negro e a construção do carnaval no Nordeste. Maceió: Edufal, 2003, p. 13-22.

ARAÚJO, Rita de Clássica Barbosa de. Festas públicas e carnavais: o negro e a cultura popular em Pernambuco. In ALMEIDA, Luiz Sávio de; CABRAL, Otávio; ARAúJO, Zezito. $O$ negro e a construção do carnaval no Nordeste. Maceió: Edufal, 2003, p. 23-54.

BARBALHO, Alexandre. Estado, mídia e identidade: políticas de cultura no Nordeste contemporâneo. Revista Alceu, v. 4, n.8, jan.-jun. 2004, p.156-167.

CANCLINI, Néstor García. As culturas populares no capitalismo. São Paulo: Brasiliense, 1982.

CUNHA, Maria Clementina Pereira. Vários Zés, um sobrenome: as muitas faces do senhor Pereira no carnaval carioca da virada do século. In Carnavais e outras $f(r)$ estas: ensaios de história social da cultura. Campinas: Editora da Unicamp/Cecult, 2002, p. 371-417.

EMTURSA. Relatório Emtursa - Carnaval de Salvador 2007. Salvador: Emtursa, 2007.

FARIA, Hamilton e NASCIMENTO, Maria Ercilia do. Desenvolvimento cultural e planos de governo. São Paulo: Pólis, 2000.

FARIAS, Edson. O desfile e a cidade: o carnaval-espetáculo carioca. Rio de Janeiro: E-papers, 2006.

FERREIRA, Felipe. O livro de ouro do carnaval brasileiro. Rio de Janeiro: Ediouro, 2004.

FISCHER, Tânia. A cidade como teia organizacional: inovações, continuidades e ressonâncias culturais - Salvador da Bahia, cidade puzzle. In MOTTA, Fernando C. Prestes e CALDAS, Miguel P. Cultura organizacional e cultura brasileira. São Paulo: Atlas, 1997, p. 254-269.

GIMENÉZ, Gilberto. Cultura popular y religión en el Anáhuac. Cidade do Mexico: Centro de Estudios Ecuménicos, 1979. 
GONÇALO JUNIOR. A ditadura da alegria. Revista da Fapesp, n. 136, São Paulo, junho de 2007, p.78-83.

MENEZES, Rogério. Um povo a mais de mil: os frenéticos carnavais de baianos e caetanos. São Paulo: Editora Página Aberta, 1994.

MIGUEZ, Paulo. A cor da festa. Cooptação \& resistência: espaços de construção da cidadania negra no carnaval baiano. In ALMEIDA, Luiz Sávio de e CABRAL, Otávio; ARAÚJO, Zezito. O negro e a construção do carnaval no Nordeste. Maceió: Edufal, 2003, p. 55-68.

MORAES, Eneida. História do carnaval carioca. Edição revista e atualizada por Haroldo Costa. Rio de Janeiro: Record, 1987.

PRESTES FILHO, Luiz Carlos. Cadeia produtiva da economia do carnaval. Rio de Janeiro: Epapers, 2009.

QUEIROZ, Maria Isaura Pereira de. Carnaval brasileiro: o vivido e o mito. São Paulo: Brasiliense, 1999.

SANTOS, Fernando Burgos Pimentel dos. Estado, política cultural e manifestações populares: A influência dos governos locais no formato dos carnavais brasileiros. Dissertação (Mestrado em Administração Pública e Governo) - Eaesp/FGV, São Paulo, 2008.

SOIHET, Rachel. A subversão pelo riso: estudos sobre o carnaval carioca da Belle Époque ao tempo de Vargas. Rio de Janeiro: Editora Fundação Getúlio Vargas, 1998.

Fernando Burgos Pimentel dos Santos é bacharel em administração pública pela FGV-Eaesp, mestre e doutorando em administração pública e governo pela FGV-Eaesp, pesquisador do Centro de Estudos em Administração Pública e Governo da FGV-Eaesp e coordenador do Curso Técnico em Gestão de Negócios Culturais do Liceu de Artes e Ofícios de São Paulo.

Artigo recebido em maio de 2010 e aceito para publicação em agosto 2010. 